\title{
Orthography-induced length contrasts in the second language phonological systems of L2 speakers of English: evidence from minimal pairs
}

Article

Accepted Version

Bassetti, B., Sokolovic-Perovic, M., Mairano, P. and Cerni, T. (2018) Orthography-induced length contrasts in the second language phonological systems of L2 speakers of English: evidence from minimal pairs. Language and Speech, 61 (4). pp. 577-597. ISSN 1756-6053 doi:

https://doi.org/10.1177/0023830918780141 Available at https://centaur.reading.ac.uk/77858/

It is advisable to refer to the publisher's version if you intend to cite from the work. See Guidance on citing.

To link to this article DOI: http://dx.doi.org/10.1177/0023830918780141

Publisher: Sage

All outputs in CentAUR are protected by Intellectual Property Rights law, including copyright law. Copyright and IPR is retained by the creators or other copyright holders. Terms and conditions for use of this material are defined in the End User Agreement. 


\section{www.reading.ac.uk/centaur}

\section{CentAUR}

Central Archive at the University of Reading

Reading's research outputs online 
Bassetti, Sokolović-Perović, Mairano, \& Cerni (2018, online first) Orthography-induced length contrasts in the second language phonological systems of L2 speakers of English: Evidence from minimal pairs. Language and Speech. DOI: $10.1177 / 002383091878014$

\title{
Orthography-induced length contrasts in the second language phonological systems of L2 speakers of English: Evidence from minimal pairs
}

\author{
Bene Bassetti ${ }^{1}$, Mirjana Sokolović-Perović ${ }^{2}$, Paolo Mairano ${ }^{1}, \&$ Tania Cerni ${ }^{1}$ \\ ${ }^{1}$ University of Warwick, UK $\quad{ }^{2}$ University of Reading, UK
}

\author{
Author Note \\ Correspondence concerning this article should be addressed to Bene Bassetti, S0.36, \\ Social Sciences Building, University of Warwick, Coventry CV4 7AL, UK. \\ Tel: (+44) (0)24 76151093 \\ E-mail: b.bassetti@warwick.ac.uk
}

\begin{abstract}
Research shows that the orthographic forms ('spellings') of second language (L2) words affect speech production in L2 speakers. The present study investigated whether English orthographic forms lead L2 speakers to produce English homophonic word pairs as phonological minimal pairs. Targets were 33 orthographic minimal pairs, that is to say homophonic words that would be pronounced as phonological minimal pairs if orthography affects pronunciation. Word pairs contained the same target sound spelled with one letter or two, such as the /n/ in finish and Finnish (both /'finIJ/ in Standard British English). To test for effects of length and type of L2 exposure, we compared Italian instructed learners of English, Italian-English late bilinguals with lengthy naturalistic exposure, and English natives. A reading aloud task revealed that Italian speakers of English $\mathrm{L}_{2}$ produce two English homophonic words as a minimal pair distinguished by different consonant or vowel length, for instance producing the target /'finis/ with a short [n] or a long [n:] to reflect the number of consonant letters in the spelling of the words finish and Finnish. Similar effects were found on the pronunciation of vowels, for instance in the orthographic pair scene-seen (both /si:n/). Naturalistic exposure did not reduce orthographic effects, as effects were found both in learners and in late bilinguals living in an English-speaking environment. It appears that the orthographic form of L2 words can result in the establishment of a phonological contrast that does not exist in the target language. Results have implications for models of L2 phonological development.
\end{abstract}


Bassetti, Sokolović-Perović, Mairano, \& Cerni (2018, online first) Orthography-induced length contrasts in the second language phonological systems of L2 speakers of English: Evidence from minimal pairs. Language and Speech.

Unlike native languages, second languages are often acquired through a mixture of spoken and written input. Recent research shows that the orthographic forms, or spellings, of second language (L2) sounds and words affect L2 speech production (Bassetti, Hayes-Harb, \& Escudero, 2015), and there have been claims that L2 orthographic forms may lead L2 speakers to establish phonological contrasts that do not exist in the target language (Bassetti, 2017). The present paper therefore aims to investigate the following question: Can orthography-induced phonological contrasts result in L2 speakers producing minimal pairs that do not exist in the target language?

\subsection{Orthographic effects on second language speech production}

The orthographic forms, that is to say spellings, of second language (L2) words and sounds can help L2 speakers perceive and produce L2 speech. For instance, learning the phonological form of words in a novel language is easier if spoken input is accompanied by written input (Davidson, 2010; Erdener \& Burnham, 2005), and written representations can help even proficient L2 speakers to better distinguish difficult L2 contrasts in pseudowords (Escudero, Hayes-Harb, \& Mitterer, 2008; Escudero \& Wanrooij, 2010). However, L2 orthographic forms can also lead to non-targetlike production, for instance when L2 speakers add a sound corresponding to a so-called 'silent letter', such as a [1] in walk (/wo:k/ in Standard British English; Bassetti \& Atkinson, 2015). The most frequently reported orthographic effect is sound substitution, for instance when Spanish $_{\mathrm{L} 1}$ speakers of American English $\mathrm{L}_{2}$ pronounce a $[t]$ or a $[d]$ in words spelled with letters $\langle t>$ or $\langle d\rangle$, which native speakers produce as flaps (Vokic, 2011). Substitutions are often associated with incongruences between grapheme-phoneme correspondences in the first and second language, whereby the two languages map the same grapheme (single letter, digraph or trigraph) onto different phonemes. For instance, English learners of L2 Spanish may produce the Spanish letter $<\mathrm{v}>$ as [v], following the grapheme-phoneme correspondences of their first language, although in Spanish the phoneme $/ \mathrm{v} /$ does not exist and $\langle\mathrm{v}>$ represents /b/ (Zampini, 1994). The next section reports recent research that argued that English orthographic forms can result in Italian speakers of English ${ }_{\mathrm{L} 2}$ making a phonological contrast in their English ${ }_{\mathrm{L} 2}$ production that does not exist in the English language because of English orthographic forms.

\subsection{Orthographic effects on the duration of consonants and vowels in Italian ${ }_{L 1}$ speakers' English $_{\mathrm{L} 2}$ production}

\subsubsection{Consonant length and its orthographic representation in English and Italian}

A geminate is a long consonant that contrasts phonemically with a singleton, its short counterpart (Davis, 2011). The Italian language has a phonemic durational contrast between singleton and geminate consonants, such that geminates have relatively longer duration (Bertinetto \& Loporcaro, 2005; Laver, 1994). For instance, the singleton $/ \mathrm{t} /$ and the geminate $/ \mathrm{t}: /$ (the /:/ symbol represents longer length) distinguish Italian minimal pairs such as /'fato/ and /'fat:o/ ('fate' and 'fact' respectively, Davis, 2011). Gemination is used to distinguish high-frequency lexical items, such as casa (/'kasa/, 'home') and cassa (/'kas:a/, 'box'), as well as different morphological forms, such as cade (/'kade/, fall-PRS.3.SG, 'he falls') and cadde (/'kad:e/, fall-PAST.3.SG, 
Bassetti, Sokolović-Perović, Mairano, \& Cerni (2018, online first) Orthography-induced length contrasts in the second language phonological systems of L2 speakers of English: Evidence from minimal pairs. Language and Speech.

DOI: $10.1177 / 002383091878014$

'he fell'). Geminate consonants are frequent, representing $19 \%$ of consonants by type and $17 \%$ by token (Goslin, Galluzzi, \& Romani, 2013). Italian gemination is mostly intervocalic, but it can also be followed by a glide (assieme, /a's:jeme/, 'together'), and for some consonants by a liquid (attrito, /a'tirito/, 'attrition'). Geminates are represented in the Italian orthography with double consonant letters, for example fatofatto (Clark \& Yallop, 1995). Double consonant letters can be found in word-final position in loanwords (miss, /mis(:)/), however, to the best of our knowledge no study has investigated acoustically how these consonants are pronounced.

English does not have a geminate-singleton contrast (Davis, 2011). So-called fake gemination occurs at morpheme boundaries, for instance the consonant $[\mathrm{n}]$ is produced as longer in fun name and in the prefixed word unnamed than in annoyed (Kaye, 2005; Oh \& Redford, 2012); however this is not a phonemic contrast. Double consonant letters can occur word-internally and word-finally, but the number of letters does not represent consonant length (Carney, 1994). That said, double consonant letters can play a role in English orthography in indicating the quality of the preceding vowel, as in $<$ latter $>/$ lætə/ versus $<$ later $>/$ leitə/, or can be used to differentiate common and proper nouns, as in chip-Chipp (ibid.). However, single and double consonant letters are different spellings of the same phoneme, such as $\langle\mathrm{t}\rangle$ and $<\mathrm{tt}>$, both representing $/ \mathrm{t} /$.

\subsubsection{Vowel length and its orthographic representation in English and Italian}

Standard British English has 12 monophthongs (Roach, 2004), which are distinguished by both quantitative and qualitative differences. For instance, comparing the tense vowel /i:/ and the lax vowel/I/, the former is longer, as well as higher and more front. Lengthening itself is allophonic, because length alone does not distinguish vowel pairs. Double vowel letters usually represent long vowels (e.g., $<$ ee $>$ in $<$ feet $>$, /fi:t/), and vowel digraphs other than double letters can also represent long vowels, e.g., <ea $>$ in $<$ jeans $>$ (/dzins/) and <e_e $>$ in $<$ scene $>$ (/sinn/, Carney, 1994).

Standard Italian has seven monophthongs (/i/, /e/, / $/$ /, /a/, / / /, /o/, /u/), and no contrastive vowel length. Vowel duration differences are not contrastive but contextually conditioned and depend on stress and syllabic structure (D'Imperio \& Rosenthall, 1999). For instance, Italian vowels are lengthened in open stressed penultimate syllables, so that the first /a/ is produced as longer in tana (/'tana/, 'den') than in tanta (/'tanta/, much-F.SG, 'much'; Farnetani \& Kori, 1986; Loporcaro, 1996). Double vowel letters in Italian occur as a consequence of morphological concatenation, for instance if the second person singular present marker $\langle-\mathrm{i}\rangle / \mathrm{i} /$ is added to a morpheme ending in $<\mathrm{i}>/ \mathrm{i} /$, as in scii, /' Sii/, ski-PRS.2.SG, '[you] ski'. Contemporary approaches consider such sounds as two quickly re-articulated vowels, that is to say two segments, each representing a syllabic nucleus (Bertinetto \& Loporcaro, 2005, but see for example Valesio, 1967, for an older approach that considered examples such as $s c i i$ and $s c i, / \int \mathrm{i} /$, 'ski' as minimal pairs distinguished by a short and a long vowel). 
Bassetti, Sokolović-Perović, Mairano, \& Cerni (2018, online first) Orthography-induced length contrasts in the second language phonological systems of L2 speakers of English: Evidence from minimal pairs. Language and Speech.

DOI: $10.1177 / 002383091878014$

\subsection{Effects of orthography on Italian ${ }_{L 1}$ speakers' production of English $_{L 2}$ consonants and vowels}

Previous research (Bassetti, 2017) found that native Italian (Italian $\left.{ }_{\mathrm{L} 1}\right)$ learners of English as a Second Language (English $\left.\mathrm{L}_{2}\right)$ with ten years' learning experience produce the same English consonant as long or short depending on the number of consonant letters in its spelling, for instance producing the [t] in kitty (/'kiti/ in Standard British English) as longer than the [t] in city (/'siti/), whereas there are no differences in duration in native English controls. This inter-orthographic effect must happen because Italians are transferring L1 grapheme-phoneme correspondences to L2 English, thereby interpreting English double consonant letters as representing geminates, as in their native orthography. This means that Italian speakers of English $_{\mathrm{L} 2}$ produce consonant length differences even though such differences do not exist in the target language English, and rely on the number of consonant letters in English orthographic forms to determine the duration of English consonants.

With regard to orthographic effects on vowel duration, Piske, Flege, MacKey, and Meador (2002) first suggested that Italian native speakers rely on orthography for the pronunciation of some vowels in the production of English $\mathrm{L}_{2}$ pseudowords, for instance pronouncing English [I] as [i] because the letter $<\mathrm{i}>$ is pronounced as [i] in Italian. Bassetti and Atkinson (2015) found that Italian $_{\mathrm{L} 1}$ learners of English $\mathrm{L}_{\mathrm{L} 2}$ with ten years' learning experience produce the same vowel as longer when spelled with a double vowel letter than a singleton vowel letter, for instance producing [u:] as longer in moon than in June (both /u:/ in Standard British English: /mu:n/ and /dzu:n/), whereas there are no duration differences in English native controls. This happens because Italians correctly recode double vowel letters such as $<00>$ as a long vowel, but also recode the $\langle\mathrm{u}\rangle$ in June as a short vowel, without realising that the grapheme $<u_{-}$e $>$represents a long vowel too. This means that these Italian ${ }_{L 1}$ learners of English $_{\mathrm{L} 2}$ (1) use length to distinguish English vowels - even though contrastive vowel length does not exist either in their native phonology or in the English phonology - and (2) rely on the number of vowel letters in L2 orthographic forms to determine the duration of vowels, overgeneralising the rule that a single vowel letter represents a short vowel to words where the single vowel letter is part of a $<$ V_e $>$ grapheme that represents a long vowel. The present paper will then expand on Italians' use of English orthographic forms in determining the length of target consonants and vowels.

\subsection{The Present Study}

This study aimed at testing whether the alternation between long and short consonants and vowels in the production of Italian $\mathrm{L}_{1}$ speakers of English $_{\mathrm{L} 2}$ should be considered as a phonological contrast in the L2 phonological systems of these speakers. We achieved this by investigating whether they produce English homophonic word pairs as minimal pairs distinguished by a short or long sound (consonant or vowel) when the same target sound is spelled with a single letter in one word and a digraph in the other.

There is previous evidence that Italian ${ }_{\mathrm{L} 1}$ speakers of English $\mathrm{L}_{2}$ produce the same target sound as short when spelled with one letter and long when spelled with two letters (for consonants, see Bassetti, 2017; for vowels, see Bassetti \& Atkinson, 2015). However, these studies used orthographic near-minimal pairs. In such pairs, the two words' spellings represent the same target consonant or vowel with one letter 
Bassetti, Sokolović-Perović, Mairano, \& Cerni (2018, online first) Orthography-induced length contrasts in the second language phonological systems of L2 speakers of English: Evidence from minimal pairs. Language and Speech.

DOI: $10.1177 / 002383091878014$

or with two letters (e.g., /t/ in city and kitty), and the sounds immediately preceding and immediately following the target sound were controlled $\left(/ \mathrm{I}_{-} \mathrm{i} /\right.$ in both city and

kitty), but the two words had differences other than the spelling of the target consonant (initial $/ \mathrm{s} /$ or $/ \mathrm{k} /$ ). With such near-minimal pairs the phonological environment is not as tightly controlled as with minimal pairs, so the effect found may theoretically be due to factors other than spelling. For instance, the words in a nearminimal pair may differ in the number of phonemes within a consonant cluster or syllable, and this may affect the duration of the target sound. This is because the duration of speech subunits decreases as the number of subunits in a larger unit increases, such as the number of consonants in a consonant cluster and the number of phonemes in a syllable (Lindblom, Lyberg \& Holmgren, 1977). The use of minimal pairs eliminates these potential confounding variables. The aim of the present study was then to test previous findings of orthographic effects on the duration of consonants and vowels in semi-minimal pairs by using orthographic minimal pairs. Furthermore, the study includes more pairs than previous studies by Bassetti and colleagues (Bassetti, 2017; Bassetti \& Atkinson, 2015). Finally, research that investigates orthographic effects on L2 production using L2 minimal pairs has mostly used pseudowords (e.g., Escudero et al., 2008; Piske et al., 2002). Research on pseudowords is important in illuminating how orthography affects phonology at the point of word learning; however, using real words is important for understanding what happens beyond initial learning.

The present study then aimed at extending previous research on effects of number of letters on target sound length by using word pairs in which the target consonant or vowel occurs in a fully controlled phonological environment, by using real words, and by using a larger number of items than previous studies. Materials consisted of 33 orthographic minimal pairs, that is to say English homophonic word pairs where the same consonant or vowel is spelled with one letter in one word and a digraph in the other, so that if number of letters affects sound length the two homophonic words would be produced as a minimal pair distinguished by a long and a short consonant or vowel. With regard to consonants, we predicted that Italian $_{\mathrm{L} 1}$ speakers of English $\mathrm{L} 2_{2}$ would produce for instance the homophonic words finish and Finnish (both /'finIf/ in Standard British English) as ['finIf] with a short [n] and ['fin:If] with a geminate [n:] respectively, because they would produce the double letters $<\mathrm{nn}>$ as a geminate [n:], according to the grapheme-phoneme correspondences of their native language. With regard to vowels, we predicted that the number of vowel letters would lead participants to apply a phonological contrast between long and short vowels to homophonic word pairs, for instance producing the homophones scene and seen (both /si:n/) with a short and a long vowel respectively, because the vowel is spelled with a single letter in one word and with a digraph in the other. Results would then demonstrate that English orthographic forms - number of letters lead Italian L1 $_{\text {speakers of English }}$ L2 to establish a singleton-geminate consonant contrast that does not exist in the English language, and to distinguish two English homophonic words by means of a short-long vowel contrast that does not exist in either their L1 or L2.

The second main aim of the study was to investigate whether naturalistic exposure reduces the impact of orthography on second language speech production. A shortcoming of current research on orthographic effects on L2 speech production is a focus on naïve learners of novel languages (e.g., Davidson, 2010; Escudero et al., 
Bassetti, Sokolović-Perović, Mairano, \& Cerni (2018, online first) Orthography-induced length contrasts in the second language phonological systems of L2 speakers of English: Evidence from minimal pairs. Language and Speech.

DOI: $10.1177 / 002383091878014$

2008; Hayes-Harb, Nicol, \& Barker, 2010; Pytlyk, 2011) and beginner learners, typically with one or two years of L2 exposure (e.g., Young-Scholten \& Langer, 2015; Zampini, 1994). There has been little research on learners with longer length of study (e.g., ten years in both Bassetti, 2017, and Bassetti \& Atkinson, 2015) and almost no research on late bilinguals who have finished studying the language (with the exception of research using pseudowords, e.g., Piske et al., 2002; but see Vokic, 2011). The present study then aimed at testing whether exposure to the target language in a naturalistic environment can reduce orthographic effects in speech production. We achieved this by comparing instructed L2 learners with late bilinguals who had been living in an English-speaking environment for an average of six years.

Finally, we investigated the relationship between the duration of short and long consonants and vowels in L2 English and in L1 Italian. We achieved this by measuring the duration of consonants and vowels in Italian minimal or near-minimal word pairs containing consonants and vowels similar to those tested in the English task, such as vano-vanno and di-zii.

\section{Method}

2.1 Design. Orthographic effects were tested using orthographic minimal word pairs, in which the same target sound (a consonant or a vowel) was spelled with a single letter or a digraph, and calculating the ratio between the duration of the consonant spelled with double letters and the duration of the consonant spelled with a single letter. Language background was a between-group factor: the learner group were Italian $_{\mathrm{L} 1}$ learners of English $\mathrm{L}_{2}$, the bilingual group were Italian $_{\mathrm{L} 1}-\mathrm{English}_{\mathrm{L} 2}$ late bilinguals, and the native group were English native speakers.

2.2 Participants. Participants were 30 Italian high-school learners of English (learners: males $=18$, mean age $=16.7$ years, $S D=0.5$ ), 30 Italian-English late bilinguals (bilinguals: males $=10$, mean age $=32.5, S D=7.3$ ), and 30 British English native speakers (natives: males $=18$, mean age: $30.8, S D=13.5$ ). No participant reported visual, reading or language difficulties.

The learner group were native speakers of the Roman variety of Standard Italian who were instructed late learners of English. In this variety, geminates are generally twice as long as singleton consonants (Esposito \& Di Benedetto, 1999). Two learners were bilingual from birth with a language that has contrastive vowel length (Hebrew or Tagalog), but their performance in the vowel production task did not differ from other participants $(p=0.637)$. Nobody had studied a second language with contrastive length. Participants were attending the fourth year at a liceo classico or scientifico (state-run non-vocational high school) in Rome. They were enrolled in eight different classes at three different schools. They were studying English language and literature as a compulsory school subject, with three one-hour sessions a week, using British English textbooks. They had been studying English on average for ten years and four months $(S D=25$ months) with a median age of onset of acquisition of six years. Their proficiency was measured using the Oxford Placement test (Allan, 1992), which tests grammar and listening comprehension. Most test-takers (54\%) performed at intermediate level (B1 or B2), another 35\% were beginners (A1 or A2) and three participants were proficient $(\mathrm{Cl}$; four participants were absent). They had little exposure to native teachers (the median reported length of study with native teachers was 6.2 months, ranging 0-156). Most participants $(n=18)$ had never been in 
Bassetti, Sokolović-Perović, Mairano, \& Cerni (2018, online first) Orthography-induced length contrasts in the second language phonological systems of L2 speakers of English: Evidence from minimal pairs. Language and Speech.

DOI: $10.1177 / 002383091878014$

an English-speaking country, the others' median stay abroad duration was 1.4 months (range 10-60 days). Respondents reported spending twice as much time listening to English (including music and movies) than reading English $\left(M d n_{\text {listening }}=4\right.$ hours per week, range: $0.5-28 ; M d n_{\text {reading }}=2$, range: 0-28). All respondents but one considered a native-like pronunciation important or very important. Participants were almost equally keen on a British English and an American pronunciation, with a slight preference for the former (on a 7-point scale where $7=$ 'very much', $M_{\mathrm{British}}=4.9, S D$ $\left.=1.4 ; M_{\text {American }}=4.6, S D=1.2\right)$.

The bilingual group were instructed late learners of English who had been living in the UK for an average of six years and seven months (range: 3-24 years), and were recruited in the UK (London or the Midlands). They were native speakers of various Southern or Central varieties of Italian, for which gemination is well described and uniformly realized (Giordano \& Savy, 2012), and they had lived in Italy until at least high-school graduation. Three participants had studied an L2 with contrastive consonant length at beginner level (Japanese or Corsican), but their performance in the consonant production task did not differ from other participants in the same group $(p=0.630)$. The bilinguals had studied English as a school subject in Italy for a median of eight years (range 3-13), with a median age of onset of acquisition of 11, mostly with Italian native teachers (four had also studied with an English native teacher). Their English proficiency was measured using self-ratings on the CEFR (Common European Framework of Reference for Languages) for five competencies (writing, spoken production, spoken interaction, reading and listening). Most participants rated themselves as 'proficient' $(\mathrm{C} 1$ or $\mathrm{C} 2$; ranging from a minimum of $59 \%$ of participants in spoken production to a maximum of $83 \%$ in reading), with the rest being intermediate (B1 or B2). Respondents reported spending three times longer reading and listening to English than Italian (Reading: $M d n_{\text {English }}=$ 15 hours per week, range: $1-84, M d n_{\text {Italian }}=5$, range: $1-15$; Listening: $M d n_{\text {English }}=14$, range: $0-84, M d n_{\text {Italian }}=4$ hours, range: $0-50$ ). They reported similar amounts of speaking in the two languages $\left(M d n_{\text {English }}=25\right.$, range: $5-70, M d n_{\text {Italian }}=20$, range: 2 $80) .79 \%$ of respondents ( $n=24$, six answers were missing) considered a native-like pronunciation important or very important, $21 \%$ did not.

The native group were native speakers of British English recruited in the UK (London or the Midlands), who mostly reported their native variety as Standard or Received Pronunciation $(n=15)$ and Southern $(n=10)$; the other varieties were Yorkshire $(n=3)$ and Midlands $(n=2)$. One participant was bilingual from birth with a language that has contrastive consonant length (Gujarati), and two further participants were bilingual from birth with a language that has contrastive vowel length (Arabic or Serbo-Croatian); a few had studied an L2 with contrastive consonant length $(n=2)$ or vowel length $(n=6)$. However none of these English speakers performed differently from the rest of the group.

Participation was voluntary and compensated. Consent was obtained from all participants, and from parents in the case of participants under the age of eighteen. The study received ethical approval by the Humanities and Social Sciences Research Ethics Committee of the University of Warwick.

2.3 Materials. Materials for the English word reading aloud task were 33 orthographic minimal or near-minimal pairs, and materials for the Italian word reading aloud task were 18 minimal or near-minimal word pairs. Materials are provided in the Appendix. 
Bassetti, Sokolović-Perović, Mairano, \& Cerni (2018, online first) Orthography-induced length contrasts in the second language phonological systems of L2 speakers of English: Evidence from minimal pairs. Language and Speech.

DOI: $10.1177 / 002383091878014$

2.3.1. English C-CC word pairs. In the $19 C-C C$ word pairs, the two words were homophones that contained the same consonant, spelled with a single letter (' $\mathrm{C}$ word') or double letters ('CC-word'), for example, finish and Finnish (both /' fin $\mathrm{S} /$ in Standard British English). The target consonants were: /t d n r s 1/, all of which can be geminated in Italian. Word pairs were selected from a complete list of all English homophonic or near-homophonic pairs that contain the same consonant spelled with single or double letters, excluding words which were rare or likely to be unfamiliar to students. In order to test for effects of legality of gemination in the L1 phonotactic rules on geminate production in English $\mathrm{L}_{2}$, eleven target consonants were in intervocalic position, whereby the Italian language licenses gemination (e.g. finishFinnish), and eight were in a position where gemination is not attested in native Italian words: word-final position (five words, e.g., $a d d$, /æd/), or syllable coda (three words, e.g., missed, /mist/).

Words had a higher written than spoken frequency $\left(M d n_{\text {Spoken }}=6.58\right.$, $\left.M d n_{\text {Written }}=11.51, V=213, p=0.02\right)$. C-words were descriptively but not significantly more frequent than CC-words $\left(M d n_{\mathrm{C} \text {-words }}=2.18, M d n_{\mathrm{CC} \text {-words }}=1.43\right.$, $W=184, p=0.71$, see Appendix; all frequencies from the British National Corpus, British National Corpus Online service). Variables that may affect consonant duration were taken into account as follows. (1) Word length: eight word pairs were monosyllabic, ten disyllabic and one trisyllabic (number of syllables may affect consonant duration, White \& Turk, 2010; but see Umeda, 1977, for counterevidence). (2) Primary lexical stress position: since in Italian closure durations tend to be longer in post-stressed than pre-stressed and unstressed positions (Payne, 2005), the target consonant was in post-stressed position in eight of the eleven polysyllabic pairs and in stressed position in the other three. (3) Gemination position: to avoid the confound of fake gemination at morpheme boundaries in English (e.g., the long [n] in unnamed, see Davis, 2011), target consonants were all tautomorphemic (i.e., morpheme internal). Also, no target consonant was intrinsically geminated in Italian (in Italian, five consonants are always pronounced as geminate in intervocalic position, such as /ts/). (4) L1-L2 orthographic congruency: to test the effects of L1 phonological forms on the pronunciation of related L2 words, of the ten CC-words that were loanwords or cognates, seven were orthographically congruent, that is, spelled with double consonant letter in both languages (e.g., roll, It. rollare,/ro'lare/, 'to roll'), and three were orthographically incongruent, that is, spelled with a double consonant in only one language (e.g., carrot, It. carota, /ka'rota/).

2.3.2 English V-VV word pairs. In the $14 V-V V$ word pairs, both words contained the same long vowel, but in one word this was spelled with a single letter ('V-word') while in the other it was spelled with a digraph ('VV-word'), for example, scene-seen (both /si:n/). The target vowels were /i: 3: o: u: ov/. Words were selected using the same criteria as for the C-CC pairs. All target vowels appeared in closed syllables, to avoid the confound of vowel lengthening in stressed word-internal open syllables (Bertinetto \& Loporcaro, 2005; D'Imperio \& Rosenthall, 1999). In most Vwords, the vowel was represented orthographically by the grapheme $<\mathrm{V}$ _e $>$ (often called 'silent e', e.g., pore, /ps:/). However, our participants and their teachers were not aware of this correspondence; therefore these were considered single letter spellings from our participants' perspective. In four of the $14 \mathrm{VV}$ words, the vowel 
Bassetti, Sokolović-Perović, Mairano, \& Cerni (2018, online first) Orthography-induced length contrasts in the second language phonological systems of L2 speakers of English: Evidence from minimal pairs. Language and Speech.

DOI: $10.1177 / 002383091878014$

was spelled with a double vowel letter ('VV-vowels'), for example, <ee> in seen. In the remaining ten words, the vowel was spelled with a digraph composed of two different letters (' $\mathrm{V}_{1} \mathrm{~V}_{2}$-vowels'), for example, <oa $>$ in road, /rəud/. Wilcoxon Signed-Rank tests revealed that words had a higher written than spoken frequency $\left(\mathrm{Med}_{\mathrm{Spoken}}=13.59\right.$, range: $0.86-456.11 ; \mathrm{Med}_{\mathrm{Written}}=30.99$, range: $1.4-369.63, \mathrm{~V}=$ $114, p=0.04)$, and that $\mathrm{V}$-words were overall more frequent than $\mathrm{VV}$-words $\left(\mathrm{Med}_{\mathrm{V} \text { - }}\right.$ words $=2.85$, range: $0.38-30.5 ;$ Med $_{\mathrm{VV} \text {-words }}=1.28$, range: $\left.0.64-4.7, W=130, p=0.14\right)$. Variables that may affect vowel duration were taken into account as follows:

(1) Number of syllables: all but one pair were monosyllabic, because number of syllables can affect vowel length (Klatt, 1973, 1976; Port, 1981). (2) Target vowel position: all but one target vowel occurred in closed syllables, as lengthening does not occur in this position in Italian (D'Imperio \& Rosenthall, 1999; Krämer, 2009). (3) Cognate status: one double vowel letter word was a loanword (jeans, pronounced /fins/ in Italian by Italians). (4) Following consonant: the target vowel was followed by a voiced consonant in 11 pair and by a voiceless consonant in the remaining three pairs, as voicing of the following consonant affects vowel length in English (Klatt, 1976).

2.3.3 Italian C-CC and V-VV word pairs. An Italian reading aloud task was used to establish the duration of long and short sounds (consonants and vowels) in the native language production of each Italian participant. Materials consisted of 18 Italian minimal or near-minimal pairs, containing target sounds that matched as much as possible those in the English word reading task: the singleton and geminate consonants /p t k d n r s 1/, and the vowels /i \& o/.

The 15 Italian $C-C C$ word pairs included ten minimal pairs that were distinguished by an intervocalic geminate or singleton consonant, for example, cade /'kade/ - cadde /'kad:e/ (respectively fall-PRS.3.SG, 'he falls', and fall-PAST.3SG, 'he fell'). The five word-final C-CC contrasts consisted of near-minimal pairs containing the same final $<\mathrm{VC}>-<\mathrm{VCC}>$ string, and included loanwords, person or place names, and acronyms, for example, bis-miss (pronounced /bis/ and /mis(:)/ in Italian by Italian speakers). This is because in Italian there is no contrastive gemination in word-final position and most consonant-final content words are loanwords, person or place names, or acronyms. These word pairs were included to test whether geminates would be produced in contexts where gemination is not attested in Italian native words. The three Italian $V$ - $V V$ pairs consisted of nearminimal pairs ending with the same $<\mathrm{V}>-<\mathrm{VV}>$ string, for example, do-zoo (respectively /do/, give-PRS.1.SG, 'I give', and /'dzoo/, 'zoo'). The words' median frequencies were as follows: Consonants: $M e d \mathrm{spoken}=0.00$, range: $0-372.05 ; M e d \mathrm{Written}$ $=0.75$, range: $0-110.83$; Vowels: $M e d$ spoken=100.17, range: $0-24021.93 ; M e d \mathrm{written}$ $=5.79$, range: $0.03-31198.41$.

2.4 Task and procedure. Participants were tested individually in a sound-attenuated or quiet room in a school in Rome or at a university in the UK. They received a printed list of English phrases or sentences, each containing an underlined target word. Phrases and sentences were used to help readers identify the target words, and were taken from the British National Corpus (British National Corpus Online service), for example, the word knows appeared inside the phrase He knows I never argue.

Participants read the target word aloud within the carrier sentence I say and pause 
Bassetti, Sokolović-Perović, Mairano, \& Cerni (2018, online first) Orthography-induced length contrasts in the second language phonological systems of L2 speakers of English: Evidence from minimal pairs. Language and Speech.

DOI: $10.1177 / 002383091878014$

three times. The carrier sentence presented the target word in nuclear position within the intonational unit, which helped to obtain consistent speech rates. The three repetitions were used to obtain a mean duration, as a single production may be unreliable (Flege, 1995). At the end of the session, Italian participants also performed the Italian word reading task. In this task, target words were presented in a short phrase or sentence extracted from the CoLFIS corpus (Bertinetto et al., 2005) or created on purpose. Each word was repeated three times in the carrier sentence Dico__senza pausa ('I say _ without pausing'). In both English and Italian word reading tasks, items were presented in one of four different orders. Responses were recorded using a Zoom H4N Pro digital recorder connected to a Shure SM10A headset microphone or an AKG HSD171 headset with dynamic microphone, or using an Alesis Multimix 12 Firewire mixer connected to a Røde NT2-A microphone.

2.5 Data analysis. Sounds that could not be acoustically analysed were eliminated from statistical analysis (English consonants: 4.4\%, or 151 out of 3420 items; English vowels: $1.3 \%$, or 34 out of 2520 ; Italian sounds: $0.4 \%$, or 4 out of 1080). This was due to sudden noises (such as a chair moving, or a participant moving a sheet of paper), or to deviant pronunciations (when a segment other than the target one was pronounced differently within the word pair). Additionally, outliers that were $2.5 S D \mathrm{~s}$ away from the participant's mean (see Selst \& Jolicoeur, 1994) we eliminated from the analysis (English consonants: 1.6\%; English vowels: $0.4 \%$; Italian consonants: $0.2 \%$ : no Italian vowel data was eliminated).

The duration of each target consonant or vowel was measured using the Praat software (Boersma \& Weenink, 2016). Consonant duration was measured following procedures in Turk, Nakai \& Sugahara (2006). For vowels, the beginning was marked as the onset of a clearly defined formant pattern in correspondence of coherent periodicity of the waveform. The end was marked where the formant pattern (especially F1 and F2) suddenly disappeared or became remarkably weaker. For each word, the mean duration of the target sound was obtained from measures of the three repetitions. Acoustic measurements were performed by four trained phoneticians (including two authors), whose intraclass correlation coefficient was $0.96,95 \% \mathrm{CI}$ $[0.95,0.97], p<0.001$.

\section{Results}

3.1 English consonant duration. For each homophonic word pair, a $C C$ : $C$ ratio was calculated by dividing the mean duration of the consonant spelled with double letters by the mean duration of the consonant spelled with a single letter. Results are shown in Table 1.

A one-way ANOVA with Language Background (Learner, Bilingual, Native) as a between-group variable revealed that the mean CC:C ratio differed across groups, $F_{l}(2,87)=30.46, p<0.001$, ges $=0.41, F_{2}(2,36)=14.57, p<0.001$, ges $=0.26$. Post hoc comparisons with Tukey adjustment revealed that the ratio was larger in the bilingual group than in the monolingual control group, and in the learner group than in the monolingual group, both $p \mathrm{~s}<0.001$. This reflects the fact that $\mathrm{C}$ - and $\mathrm{CC}$ consonants had almost the same duration in the English group (mean $\mathrm{CC}: \mathrm{C}$ ratio $=$ 
Bassetti, Sokolović-Perović, Mairano, \& Cerni (2018, online first) Orthography-induced length contrasts in the second language phonological systems of L2 speakers of English: Evidence from minimal pairs. Language and Speech.

DOI: $10.1177 / 002383091878014$

$1.06, S D=0.26)$. The two L2 speaker groups (bilinguals and learners) did not differ, $p$ $=0.857$, reflecting the fact that they had almost the same CC:C ratio $\left(M_{\text {learners }}=1.27\right.$, $S D=0.44 ; M_{\text {bilinguals }}=1.26, S D=0.42$ ).

To test whether the legality of the position of the target consonant in Italian affected gemination in the Italian groups, a mixed ANOVA was run with Language Background (Learner, Bilingual, Native) as a between-group factor and Consonant Position (Legal, Illegal) as a within-group factor (see Table 1). The main effect of Language Background, $F_{l}(2,87)=29.22, p<0.001$, ges $=0.25, F_{2}(2,34)=23.52, p$ $<0.001$, ges $=0.39$, and the main effect of Consonant Position, $F_{l}(1,87)=54.31, p<$ 0.001 , ges $=0.24, F_{2}(1,17)=16.69, p<0.001$, ges $=0.35$, were qualified by an interaction, $F_{l}(2,87)=18.35, p<0.001$, ges $=0.17, F_{2}(2,34)=12.05, p<0.001$, ges $=0.25$. Post hoc comparisons with Tukey adjustment revealed that the CC:C ratio was larger in legal than illegal positions in the learner group, $p<0.001$, and in the bilingual group, $p<0.001$, showing that Italians produce longer consonants in positions where gemination is attested in Italian native words than in positions where it is not. Target consonant position had no effect on duration ratio in the English native group, $p=0.226$.

Table 1

Mean CC:C ratio (SD in brackets) for consonant duration as a Function of Language Background (English native speakers, Italian learners of English ${ }_{L 2}$, Italian $_{L^{-}}$ English $_{L 2}$ bilinguals) and Position (Legal in Italian, Illegal in Italian)

\begin{tabular}{|c|c|c|c|}
\hline \multirow[b]{2}{*}{ Language Background } & \multicolumn{2}{|c|}{ Position } & \multirow[b]{2}{*}{ Overall } \\
\hline & $\begin{array}{l}\text { Legal in } \\
\text { Italian }\end{array}$ & $\begin{array}{l}\text { Illegal in } \\
\text { Italian }\end{array}$ & \\
\hline English native speakers & $1.04(0.21)$ & $1.07(0.30)$ & $1.06(0.26)$ \\
\hline Italian learners of English $\mathrm{L}_{\mathrm{L}}$ & $1.39(0.49)$ & $1.12(0.29)$ & $1.27(0.44)$ \\
\hline Italian $_{\mathrm{L} 1}-$ English $_{\mathrm{L} 2}$ bilinguals & $1.38(0.45)$ & $1.11(0.34)$ & $1.26(0.42)$ \\
\hline
\end{tabular}

3.2 English vowel duration. For each homophonic word pair, a $V V: V$ ratio was calculated by dividing the mean duration of the vowel spelled with a vowel digraph by the duration of the vowel spelled with single letter. Table 2 shows the results.

A one-way ANOVA with Language Background (Learner, Bilingual, Native) as a between-group variable revealed that the mean $\mathrm{VV}: \mathrm{V}$ ratio differed across groups in the by-subject analysis, $F_{l}(2,87)=6.02, p=0.004$, ges $=0.12, F_{2}(2,26)=2.94, p$ $=0.07$, ges $=0.08$. Post hoc comparisons with Tukey adjustment revealed that the ratio was larger in the bilingual group than in the monolingual control group, $p=$ 0.007 , and in the learner group than in the monolingual group, $p=0.003$. This reflects the fact that $\mathrm{V}$ - and $\mathrm{VV}$-vowels had almost the same duration in the English group (mean VV:V ratio $=1.05, S D=0.23$ ). The two L2 speaker groups (bilinguals and learners) did not differ, $p=0.950$, as they had almost the same $\mathrm{VV}: \mathrm{V}$ ratio $\left(M_{\text {learners }}=\right.$ $\left.1.12, S D=0.33 ; M_{\text {bilinguals }}=1.11, S D=0.37\right)$.

To test whether there was a difference in the duration of vowels spelled with a double vowel letter (VV, e.g., seen) and vowels spelled with a digraph composed of two different letters $\left(\mathrm{V}_{1} \mathrm{~V}_{2}\right.$, e.g., soul $)$, a mixed ANOVA was run with Language Background (Learner, Bilingual, Native) as a between-group factor and Type of Vowel Digraph (double letters or $\mathrm{VV}$, two letters or $\mathrm{V}_{1} \mathrm{~V}_{2}$ ) as a within-group factor (see Table 2). The main effect of Language Background was significant in the by- 
Bassetti, Sokolović-Perović, Mairano, \& Cerni (2018, online first) Orthography-induced length contrasts in the second language phonological systems of L2 speakers of English: Evidence from minimal pairs. Language and Speech.

DOI: $10.1177 / 002383091878014$

subject analysis and approached significance in the by-item analysis, $F_{l}(2,87)=5.32$, $p=0.007$, ges $=0.64, F_{2}(2,24)=3.09, p=0.064$, ges $=0.09$. The main effect of Type of Digraph was significant in the by-subject analysis, $F_{I}(1,87)=5.43, p=0.022$, ges $=0.03, F_{2}(1,12)=0.82, p=0.382$, ges $=0.04$. However, both main effects were qualified by an interaction in the by-subject analysis, $F_{l}(2,87)=3.16, p=0.048$, ges $=0.03, F_{2}(2,24)=1.64, p=0.214$, ges $=0.05$. This shows that $\mathrm{VV}$-vowels were longer than $\mathrm{V}_{1} \mathrm{~V}_{2}$ vowels in both the learner group $(p<0.001)$ and the bilingual group $(p=0.006)$. Type of vowel spelling had no effect on native speakers' vowel duration, $p=0.995$.

\section{Table 2}

Mean VV:V Ratio (SD in brackets) for vowel duration as a Function of Language Background (English native speakers, Italian learners of English ${ }_{L 2}$, Italian ${ }_{L 1^{-}}$ English $h_{L 2}$ bilinguals) and Type of Digraph $\left(V V=\right.$ double vowel letter, $V_{1} V_{2}=$ two vowel letters)

\begin{tabular}{|c|c|c|c|}
\hline \multirow[b]{2}{*}{ Language Background } & \multicolumn{2}{|c|}{ Type of digraph } & \multirow{2}{*}{ Overall } \\
\hline & VV & $\mathbf{V}_{1} \mathbf{V}_{2}$ & \\
\hline English native speakers & $1.05(0.17)$ & $1.04(0.25)$ & $1.05(0.23)$ \\
\hline Italian learners of English ${ }_{\mathrm{L} 2}$ & $1.13(0.38)$ & $1.11(0.31)$ & $1.12(0.33)$ \\
\hline Italian $_{\mathrm{L} 1}-$ English $_{\mathrm{L} 2}$ bilinguals & $1.20(0.53)$ & $1.08(0.27)$ & $1.11(0.37)$ \\
\hline
\end{tabular}

3.3 Duration in Italian ${ }_{\mathrm{L1}}$ and in English $_{\mathrm{L2}}$. Durations of Italian consonants and vowels were measured in the same way as English ones. For each Italian word pair, a long sound-to-short sound ratio (CC:C or VV:V) was calculated by dividing the mean duration of the target sound spelled with a digraph by the duration of the single-letter counterpart. The mean CC:C ratio in Italian was $2.04(S D=0.97 ; 2.47$ in intervocalic position; 1.17 in word-final position). The mean $\mathrm{VV}: \mathrm{V}$ ratio was $1.60(S D=0.49)$.

3.4. Orthographic consistency. In order to disentangle the effects of the orthographic form of words from the effects of the phonological form of related words in the native language, two repeated-measures t-tests compared the CC:C ratios in L1-L2 orthography-congruent cognate or loanword pairs with the ratio of the other word pairs containing the same target consonant or vowel. With regard to consonants, there were four pairs containing a target sound spelled $\langle\mathrm{VnnV}\rangle$ : one contained an orthographically congruent word (Finnish, It. finnico, /'fin:iko/), one contained an incongruent word (manners, It. maniere, /ma'njere/), and two contained no cognates (tenner, banned). While level of L1-L2 orthographic congruency affected consonant duration, $\mathrm{F}(2,176)=18.27, p<0.001$, ges $=0.08$, results were mixed, as the orthography-congruent pair had a larger ratio than both the incongruent pair and the unrelated pairs (both $p \mathrm{~s}=0.001$ ), but the incongruent pair did no differ from the unrelated pairs $(p=0.448)$. Also, no differences were found between the pair containing the orthography-incongruent carrot (It. carota, /ka'rota/) and the other $<\mathrm{VrrV}>$ pair, $p=0.063$, and the incongruent word pair had a descriptively larger $\mathrm{CC}: \mathrm{C}$ ratio than the unrelated pair. With regard to vowels, the $\mathrm{VV}: \mathrm{V}$ ratio was smaller in the pair containing the loanword jeans (/dzins/) than the other word pair 
Bassetti, Sokolović-Perović, Mairano, \& Cerni (2018, online first) Orthography-induced length contrasts in the second language phonological systems of L2 speakers of English: Evidence from minimal pairs. Language and Speech.

DOI: $10.1177 / 002383091878014$

containing $<\mathrm{CeaC}>, p<0.001$.

\section{Discussion}

Results confirmed the hypothesis that Italian $_{\mathrm{L} 1}$ speakers of English $_{\mathrm{L} 2}$ produce English homophonic word pairs as minimal pairs distinguished by a long or short sound (consonant or vowel) when the same target sound is spelled with a single letter in one word and a digraph in the other. It is argued that the alternation between long and short consonants in these speakers' production is evidence of a geminate-singleton phonological contrast in their L2 phonological systems that does not exist in the target language. The alternation between long and short vowels is evidence that the orthographic forms of English words lead these L2 speakers to apply a long-short phonological contrast to word pairs that are homophonic for native speakers, because of their spelling. More details are provided in the next two sections.

\subsection{Effects of consonant spelling on consonant duration in orthographic minimal pairs}

The Italian $\mathrm{L}_{\mathrm{L} 1}$ speakers of English $_{\mathrm{L} 2}$ produced the same consonant 1.26-1.27 times as long when spelled with double letters than when spelled with a single letter, and specifically 1.38-1.39 times as long in intervocalic contexts. No effects of orthography were found in native speakers, whose mean $\mathrm{CC}: \mathrm{C}$ ratio was close to one. These results are in line with previous findings that compared near-minimal pairs such as city-kitty (Bassetti, 2017), confirming that Italian native speakers decode English double consonant letters as geminate consonants, in line with the graphemephoneme correspondence rules of their native orthography, where $<\mathrm{CC}>$ corresponds to geminate $/ \mathrm{C}: /$.

In line with literature on the phonetic correlates of gemination in Italian, when tested in their native language, this study's native speakers of the Roman variety of Italian produced geminates that were twice as long as singleton consonants. These speakers' geminate-singleton ratio is then larger in Italian $_{\mathrm{L} 1}$ than in English $\mathrm{L}_{2}$. There may be various reasons for this smaller ratio in English, including probably the interference between orthographic input that contains double consonant letters and native spoken input where longer consonants are not attested.

Crucially, the present study found this difference in duration in orthographic minimal pairs, that is to say homophonic words that contain the same target sound spelled with a single letter or a digraph. Controlling the phonological environment by means of the use of minimal pairs supports the claim that the effect can only be attributed to spelling. The relationship between the Italians' two categories and the native speakers' category were slightly different from previous findings. Bassetti (2017) reported that Italian ${ }_{\mathrm{L} 1}{\text { speakers of } \text { English }_{\mathrm{L} 2} \text { have established two phonological }}$ categories, one shorter and one longer than the native English category. Results from the present study revealed that consonants spelled with double letters were produced as longer in the Italian participants $\left(M_{\text {bilinguals }}=103 \mathrm{~ms}, S D=45 ; M_{\text {learners }}=100, S D=\right.$ $39)$ than the native speakers $(M=89, S D=45)$, but consonants spelled with single letter in the Italian participants were not shorter than in the native speakers $\left(M_{\text {bilinguals }}\right.$ $=89, S D=45 ; M_{\text {learners }}=85, S D=37 ; M_{\text {natives }}=87, S D=46$ ). Whatever the phonetic durations, it is safe to conclude that, in the phonological system of these English $\mathrm{L}_{2}$ speakers, words such as finish and Finnish are in fact minimal pairs -- /'finif/vs. /'fin:If/ -- distinguished by a singleton or geminate consonant. Since the two words 
Bassetti, Sokolović-Perović, Mairano, \& Cerni (2018, online first) Orthography-induced length contrasts in the second language phonological systems of L2 speakers of English: Evidence from minimal pairs. Language and Speech.

DOI: $10.1177 / 002383091878014$

only differ in the number of letters in the spelling of the target sound, this is an orthography-induced phonological contrast.

Apart from the effects of L1 and L2 orthography, L1 phonological constraints also played a role. Some of the target consonants appeared in contexts where gemination is legal in native Italian words -- intervocalic position -- and others in positions that are illegal in Italian native words -- word-final or syllable coda. The mean CC:C ratios in Italians' English ${ }_{\mathrm{L} 2}$ production were 1.39 in legal positions and 1.12 in illegal position. The ratio in intervocalic position is then similar to that reported in Bassetti's study of near-minimal pairs, where all targets were intervocalic (Bassetti, 2017). The ratio is also smaller than the Roman participants' Italian CC:C

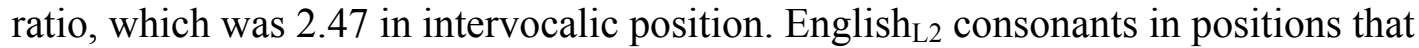
are illegal in Italian were also lengthened, but to a much smaller extent than those in legal position. This reflects a similar pattern in Italian participants' production of Italian geminates, whose $\mathrm{CC}: \mathrm{C}$ ratio in illegal position was just 1.17. It appears that the legality or illegality - according to L1 phonotactic rules -- of the resulting geminate consonant in the first language modulates a gemination process in L2 English, which appears to occur much less or not at all in contexts where the geminate consonant would not be legal in a native language word. All these phenomena show that the orthographic effect is not a blanket effect, but there is an interaction between L2 orthography, L1 orthography-phonology correspondences, and L1 phonology.

Although the legality of the position of gemination in Italian phonology affected Italians' English ${ }_{\mathrm{L} 2}$ geminate durations, other relations between L1 and L2 gemination were not found, as follows. First, gemination occurred both in cognate words and in unrelated words, and comparisons of cognate and non-cognate words produced mixed results. This confirmed previous findings (Bassetti, 2017) that gemination in an English word is not simply caused by gemination in a native cognate word, although the presence of a cognate word with gemination may reinforce the orthographic effect. Second, participants' English $\mathrm{L}_{2} \mathrm{CC}$ : C ratio was much smaller than their Italian $\mathrm{L}_{1} \mathrm{CC}: \mathrm{C}$ ratio. It appears that Italians' gemination in English is present, but not as strong as in their native language, probably because such durational differences are not present in the spoken input.

Length of exposure to the target language in a naturalistic context did not modulate the effects of orthography on consonant production, as instructed L2 learners and late bilinguals with an average residence of over six years in a British English-speaking environment had almost identical CC:C ratios. It was expected that orthographic forms would affect learners more than bilinguals, because instructed learners' L2 input includes both large amounts of orthographic input and spoken input produced by other non-native speakers (classmates and teachers) who may also produce geminates. The late bilinguals instead had been exposed to a native-speaking environment for years, and native speakers do not produce longer or shorter consonants in relation to their spelling, as shown both by English participants in this study and elsewhere (Bassetti, 2017). However, it is also possible that current learners of English are exposed to more spoken input than previous generations, and indeed learners reported spending twice as long listening to than reading English, as this included pop songs, movies and the internet. The late bilinguals in this study learnt English earlier, and this likely stronger reliance on written input during the learning process may be one reason why orthographic effects were found in spite of lengthy naturalistic exposure.

The fact that learners and bilinguals did not differ is also interesting because targets were real words. Research shows that experienced L2 speakers are affected by 
Bassetti, Sokolović-Perović, Mairano, \& Cerni (2018, online first) Orthography-induced length contrasts in the second language phonological systems of L2 speakers of English: Evidence from minimal pairs. Language and Speech.

DOI: $10.1177 / 002383091878014$

orthographic forms when learning pseudowords (e.g., Escudero et al., 2008). Finding such effects in real words shows that orthographic effects extend well beyond the initial stage of learning, and continue to influence the production of known words even after years of exposure to a native-speaking environment. It appears that once the phonological contrast between geminates and singletons is established during the learning process, Italian speakers of English continue to make this contrast in spite of its absence in the spoken input they are exposed to.

\subsection{Effects of vowel spelling on vowel duration in orthographic minimal pairs}

While orthography did not affect vowel duration in English native speakers,

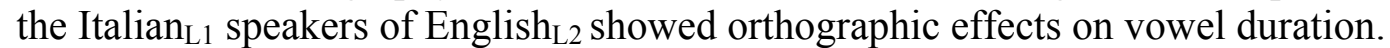
Italian participants produced the same English target vowel on average 1.11-1.12 times as long when spelled with a vowel digraph than when spelled with a single vowel letter. Effects of orthography on duration were much weaker than in consonants, possibly reflecting the facts that vowel length is not contrastive in Italians' native phonology, that English vowels differ qualitatively as well as quantitatively, and that the correspondence between number of letters and English vowel length is far less regular than the correspondence between number of letters and Italian consonant length.

In line with predictions, Italian $\mathrm{L}_{1}$ speakers of English $_{\mathrm{L} 2}$ produced a longer vowel in English words spelled with a double vowel letter than in homophonic words spelled with a single vowel letter, for instance producing a longer vowel in seen than in scene. Italian participants' long vowels were on average 1.11-1.12 times as long as short vowels, in line with previous findings of 1.14 times longer vowels with nearminimal pairs (Bassetti \& Atkinson, 2015). This confirms that Italian native speakers use vowel length contrastively in L2 English, even though vowel length is not contrastive in English, and produce the same vowel as longer or shorter depending on the number of letters present in the spelling of the word. As with the consonant data above, these results confirm and extend previous findings, as the use of minimal instead of near-minimal pairs allows us to better attribute the cause to orthography, rather than other potential confounding variables.

Italian participants, however, did not apply orthographic rules uniformly, but their production seemed to reflect a number of other factors, possibly including their use of statistical probabilities in English grapheme-phoneme correspondences, and effects of Italian phonology, as explained below. First, the Italians' English VV:V ratio was significantly larger in vowels spelled with double letters than with vowel digraphs composed of two different vowel letters, probably reflecting the fact that $<\mathrm{VV}>$ mostly represents a long vowel /V:/ in English orthography, whereas correspondences between other types of digraphs and vowel length are less regular. Second, many of the single-letter vowels in this study in fact contained the digraph

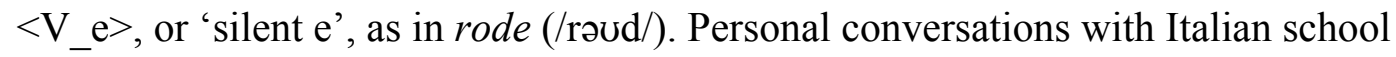
teachers confirmed that Italian learners are not aware of this non-linear correspondence. However, they may have acquired the correspondence implicitly. Third, in Italian words $<\mathrm{VV}>$ sequences correspond to quickly re-articulated vowels (Bertinetto \& Loporcaro, 2005), as in sci-scii (/Si/, 'ski', and /'Sii/, ski-PRS.2.SG, '[you] ski') discussed above. This orthography-phonology correspondence in Italian could reinforce Italians' tendency to recode English $\mathrm{L}_{2}<\mathrm{VV}>$ sequences as long vowels, or possibly as quickly re-articulated vowels. The comparison between the $\mathrm{VV}: \mathrm{V}$ ratio in Italian participants' production of L1 Italian and L2 English provides 
Bassetti, Sokolović-Perović, Mairano, \& Cerni (2018, online first) Orthography-induced length contrasts in the second language phonological systems of L2 speakers of English: Evidence from minimal pairs. Language and Speech.

DOI: $10.1177 / 002383091878014$

further clues. Italians' VV-vowels were 1.6 times as long as V-vowels in their native language Italian, compared with 1.11-1.12 times in English production.

Finally, as with consonant results, length of exposure to the target language in a naturalistic context did not modulate orthographic effects on vowel production, as no differences were found in the $\mathrm{VV}: \mathrm{V}$ ratio between learners and bilinguals.

\section{Conclusion}

This study shows that the orthographic forms of L2 words can lead L2 speakers to produce homophonic word pairs as minimal pairs. In the case of long and short consonants, the effect of number of letters on the production of target consonants results in relatively large differences in duration between long and short consonants. This is an inter-orthographic effect, as L2 graphemes are recoded according to native grapheme-phoneme correspondences, resulting in a geminate-singleton distinction in L2 English. In the case of vowels, orthographic effects are less conspicuous but still present, as Italians rely on number of vowel letters to determine the duration of vowels, and produce the same vowel as shorter if spelled with a single vowel letter, and as longer if spelled with a double vowel letter or - to a lesser extent - if spelled with a vowel digraph, and including vowels spelled with the digraph $\langle\mathrm{V}$ _e $>$. This is then an intra-orthographic effect, as L2 speakers use vowel length contrastively in L2 English, due to their misapplication of L2 grapheme-phoneme correspondences.

In the case of consonants, it is clear that Italians have two distinct categories for short consonants and long consonants, and they produce one or the other depending on the spelling of the target sounds. With vowels, the situation is more complex, and future research should disentangle various issues. Such effects are present both in instructed learners with little exposure to English outside school, and in bilinguals with years of exposure to an English-speaking environment. It is then possible to conclude that, at least with regard to consonants, Italian native speakers have established a phonological contrast in their L2 English phonological systems that does not exist in English native speakers' systems, as demonstrated by the production of homophonic pairs as phonological minimal pairs.

The non-targetlike consonant pronunciations found in this study show all the properties Bassetti (2008) suggested for orthography-induced L2 speech production: (a) gemination cannot be attributed to the native speakers' speech L2 learners are exposed to, because this study as well as previous ones (Bassetti, 2017) show that English native speakers do not produce geminates in morpheme internal position; (b) gemination cannot be explained by the influence of L1 phonological forms, because it occurs in words other than cognates and loanwords; (c) gemination does not occur in the early phonologies of English native-speaking children; (d) gemination is not traceable to universals of phonological acquisition, because it is a marked feature, meaning that it is less commonly found in the languages of the world (Maddieson, 1984, found it in less the $4 \%$ of the languages he surveyed), and (e) gemination occurs consistently with related orthographic forms and reflects L1 grapheme-phoneme correspondence rules. Obviously, orthography-induced geminates may be present in the acoustic input of instructed learners, as fellow students -- and possibly non-native teachers -- may produce geminate consonants in the classroom. Future research could then investigate whether gemination occurs in instructed learners who only studied with English native teachers.

Results have implications for models of L2 phonology acquisition. Current models, such as the Perceptual Assimilation Model (Best \& Tyler, 2007) and the Speech Learning Model (Flege, 1995), do not include orthographic input. However, 
Bassetti, Sokolović-Perović, Mairano, \& Cerni (2018, online first) Orthography-induced length contrasts in the second language phonological systems of L2 speakers of English: Evidence from minimal pairs. Language and Speech.

DOI: $10.1177 / 002383091878014$

the present results show that orthographic input plays an important role in determining which phonological contrasts L2 speakers make. Importantly, as argued by Bassetti (2017), these models focus on explaining the acquisition of L2 contrasts that do not exist in the learners' native phonological system, with a special focus on situations where the native language has one category and the second language has two. However, the present consonant results show that L2 speakers can also establish two categories in their own second language system where the second language only has one. Models of L2 phonological development then need to discuss orthography's role in establishing phonological contrasts, including those that do not exist in the target phonological system.

The study opens avenues for future research. Having shown that double letters result in the establishment of a phonological contrast in L2 speakers' phonological systems, it would be interesting to examine variables that may modulate this effect. The present study found no effects of naturalistic exposure in a comparison of instructed learners and late bilinguals with years of residence abroad. However, there may be effects of relative amount of use of the native and second language, of proficiency levels, and of other speaker-level variables such as age of onset. Wordlevel variables may also play a role, for instance L1-L2 orthographic congruency (which produced mixed results in this and previous studies by Bassetti and colleagues), and written and spoken frequencies. All these variables were reported but not analysed in this study, due to small sample sizes. Finally, the study revealed a potentially novel finding regarding Italians' native speech production, namely that Italians seem to produce geminates in word-final position in loanwords, and future research may investigate this phenomenon further.

\section{Acknowledgments}

The authors are grateful to Alessandra Panicacci for help with data collection, to Emanuela Buizza and Valentina De Iacovo for help with acoustic analyses, to Jackie Masterson for comments on a previous version of the paper, and to all students and their teachers for taking part.

\section{Funding}

This work was supported by a Leverhulme Trust Research Grant [grant number: RPG 2013 180] awarded to the first author and to Jackie Masterson. 
Bassetti, Sokolović-Perović, Mairano, \& Cerni (2018, online first) Orthography-induced length contrasts in the second language phonological systems of L2 speakers of English: Evidence from minimal pairs. Language and Speech.

DOI: $10.1177 / 002383091878014$

\section{References}

Allan, D. (1992). Oxford Placement Test. Oxford: Oxford University Press.

BADIP. Banca dati dell'italiano parlato, Language server of Karl-FranzensUniversität Graz. Retrived from http://languageserver.uni-graz.at/badip

Bassetti, B. (2008) Orthographic input and second language phonology. In T. Piske \& M. Young-Scholten (Eds.), Input matters in SLA (pp. 191-206). Clevedon, UK: Multilingual Matters.

Bassetti, B. (2017). First and second language orthographies affect second language phonology: The orthography-induced singleton-geminate consonant contrast in second language speakers of English. Journal of Experimental Psychology: Learning, Memory, and Cognition, 43(11), 1835-1842.

Bassetti, B., \& Atkinson, N. (2015). Effects of orthographic forms on pronunciation in experienced instructed second language learners. Applied Psycholinguistics, 36(2), 67-91.

Bassetti, B., Hayes-Harb, R., \& Escudero, P. (2015). Second language phonology at the interface between acoustic and orthographic input. Applied Psycholinguistics, 36(1), 1-6.

Bertinetto, P. M., Burani, C., Laudanna, A., Marconi, L., Ratti, D., Rolando, C., \& Thornton, A. M. (2005). Corpus e lessico di frequenza dell'italiano scritto (CoLFIS) [Written Italian corpus and lexical frequencies]. Retrieved from http://linguistica.sns.it/CoLFIS/Home.htm

Bertinetto, P. M., \& Loporcaro, M. (2005). The sound pattern of Standard Italian, as compared with the varieties spoken in Florence, Milan and Rome. Journal of the International Phonetic Association, 35(2), 131-151.

Best, C. T., \& Tyler, M. D. (2007). Nonnative and second-language speech perception: Commonalities and complementarities. In M. J. Munro \& O.-S. Bohn (Eds.), Second language speech learning: The role of language experience in speech perception and production (pp. 13-34). Amsterdam: John Benjamins.

Boersma, P., \& Weenink, D. (2016). Praat: Doing phonetics by computer (Version 6.0.19). Retrieved from http://www.praat.org/

British National Corpus Online service. Retrieved from http://corpora.lancs.ac.uk/BNCweb/

Canepari, L. (2009). Dizionario di pronuncia italiana. Bologna, Italy: Zanichelli Editore.

Carney, E. (1994). A survey of English spelling. Oxford, UK: Routledge.

Clark, J., \& Yallop, C. (1995). An introduction to phonetics and phonology. Oxford, UK: Blackwell Publishing.

D'Imperio, M., \& Rosenthall, S. (1999). Phonetics and phonology of main stress in Italian. Phonology, 16(1), 1-28.

Davidson, L. (2010). Phonetic bases of similarities in cross-language production: Evidence from English and Catalan. Journal of Phonetics, 38(2), 272-288.

Davis, S. (2011). Geminates. In M. van Oostendrop, C. J. Ewen, E. Hume, \& K. Rice (Eds.), The Blackwell companion to phonology (Vol. 2. Suprasegmental and prosodic phonology, pp. 873-897). Oxford, UK: Wiley-Blackwell.

Erdener, V. D., \& Burnham, D. K. (2005). The role of audiovisual speech and orthographic information in nonnative speech production. Language Learning, 55(2), 191-228. 
Bassetti, Sokolović-Perović, Mairano, \& Cerni (2018, online first) Orthography-induced length contrasts in the second language phonological systems of L2 speakers of English: Evidence from minimal pairs. Language and Speech.

DOI: $10.1177 / 002383091878014$

Escudero, P., Hayes-Harb, R., \& Mitterer, H. (2008). Novel second-language words and asymmetric lexical access. Journal of Phonetics, 36(2), 345-360.

Escudero, P., \& Wanrooij, K. (2010). Learning the phonological forms of new words: Effects of orthographic and auditory input. Language and Speech, 53(3), 361381.

Esposito, A., \& Di Benedetto, M. G. (1999). Acoustical and perceptual study of gemination in Italian stops. Journal of the Acoustical Society of America, 106(4), 2051-2062.

Farnetani, E., \& Kori, S. (1986). Effects of syllable and word structure on segmental durations in spoken Italian. Speech Communication, 5(1), 17-34.

Flege, J. E. (1995). Second language speech learning: Theory, findings and problems. In W. Strange (Ed.), Speech perception and linguistic experience: Theoretical and methodological issues (pp. 233-277). Timonium, MD: York Press.

Giordano, R., \& Savy, R. (2012). Sulla consonantizzazione del consonantismo dell'italiano: Consonanti geminate, rafforzate e fricative alveolari in contesto intervocalico. In P. Bianchi, N. De Blasi, C. De Caprio, \& F. Montuori (Eds.), La variazione nell'italiano e nella sua storia: Varietà e varianti linguistiche e testuali (pp. 431-446). Firenze, Italy: Franco Cesati Editore.

Goslin, J., Galluzzi, C., \& Romani, C. (2014). PhonItalia: A phonological lexicon for Italian. Behavior Research Methods, 46(3), 872-886.

Hayes-Harb, R., Nicol, J., \& Barker, J. (2010). Learning the phonological forms of new words: Effects of orthographic and auditory input. Language and Speech, 53(3), 367-381.

Kaye, A. S. (2005). Gemination in English. English Today, 21, 43-55.

Klatt, D. (1973). Interaction between two factors that influence vowel duration. Journal of the Acoustical Society of America, 54(4), 1102-1104.

Klatt, D. (1976). Linguistic uses of segmental duration in English: Acoustic and perceptual evidence. Journal of Acoustic Society of America, 59, 1208-1221.

Krämer, M. (2009). The phonology of Italian. Cambridge, UK: CUP.

Laver, J. (1994). Principles of phonetics. Cambridge, UK: Cambridge University Press.

Lindblom, B., Lyberg, B., \& Holmgren, K. (1981). Durational patterns of Swedish phonology: Do they reflect short-term motor memory processes?

Bloomington, Indiana: Indiana University Linguistics Club Publications.

Loporcaro, M. (1996). On the analysis of geminates in Standard Italian and Italian dialects. In B. Hurch \& R. Rhodes (Eds.), Natural phonology: The state of the art. Berlin, Germany: de Gruyter.

Maddieson, I. (1984). Patterns of sounds. Cambridge: Cambridge University Press.

Oh, G. E., \& Redford, M. A. (2012). The production and phonetic representation of fake geminates in English. Journal of Phonetics, 40(1), 82-91.

Payne, E. M. (2005). Phonetic variation in Italian consonant gemination. Journal of the International Phonetic Association, 35(2), 153-181.

Port, R. F. (1981). Linguistic timing factors in combination. The Journal of the Acoustical Society of America, 69(1), 262-274.

Piske, T., Flege, J. E., MacKay, I. R. A., \& Meador, D. (2002). The production of English vowels by fluent early and late Italian-English bilinguals. Phonetica, $59,49-71$.

Pytlyk, C. (2011). Shared orthography: Do shared written symbols influence the perception of L2 sounds? Modern Language Journal, 54(4), 541-557. 
Bassetti, Sokolović-Perović, Mairano, \& Cerni (2018, online first) Orthography-induced length contrasts in the second language phonological systems of L2 speakers of English: Evidence from minimal pairs. Language and Speech.

DOI: $10.1177 / 002383091878014$

Roach, P. (2004). British English: Received pronunciation. Journal of the International Phonetic Association, 34(21), 239-245.

Selst, M. V., \& Jolicoeur, P. (1994). A solution to the effect of sample size on outlier elimination. Quarterly Journal of Experimental Psychology, 47(3), 631-650.

Turk, A., Nakai, S., \& Sugahara, M. (2006). Acoustic segment durations in prosodic research: A practical guide. In S. Sudhoff, D. Lenertova, R. Meyer, S. Pappert, P. Augurzky, I. Mleinek, N. Richter, \& J. Schließer (Eds.), Methods in empirical prosody research (pp. 1-28). Berlin, Germany: de Gruyter.

Umeda, N. (1977). Consonant duration in American English. Journal of the Acoustical Society of America, 61(3), 846-858.

Valesio, P. (1967). Geminate vowels in the structure of contemporary Italian. Lingua, $18,251-270$.

Vokic, G. (2011). When alphabets collide: Alphabetic first-language speakers' approach to speech production in an alphabetic second language. Second Language Research, 27(3), 391-417.

White, L., \& Turk, A. (2010). English words on the Procrustean bed: Polysyllabic shortening reconsidered. Journal of Phonetics, 38(3), 459-471.

Young-Scholten, M., \& Langer, M. (2015). The role of orthographic input in second language German: Evidence from naturalistic adult learners' production. Applied Psycholinguistics, 36(01), 93-114.

Zampini, M. L. (1994). The role of native language transfer and task formality in the acquisition of Spanish spirantization. Hispania, 77(3), 470-481. Retrieved from http: Ilcervantesvirtual.com/servlet/SirveObras/13540511434137617422202/p0 000009.htm\#i_14_ 
Bassetti, Sokolović-Perović, Mairano, \& Cerni (2018, online first) Orthography-induced length contrasts in the second language phonological systems of L2 speakers of English: Evidence from minimal pairs. Language and Speech.

DOI: $10.1177 / 002383091878014$

\section{Appendix.}

English word reading aloud task materials. Word frequencies from BNCweb.

\begin{tabular}{|c|c|c|c|c|c|}
\hline \multicolumn{6}{|c|}{ Consonants } \\
\hline $\begin{array}{c}\text { Target } \\
\text { consonant }\end{array}$ & $\begin{array}{c}\text { Spoken } \\
\text { form }\end{array}$ & $\begin{array}{c}\begin{array}{c}\text { Written } \\
\text { forms }\end{array} \\
\end{array}$ & $\begin{array}{c}\text { Spoken } \\
\text { frequency }\end{array}$ & $\begin{array}{c}\text { Written } \\
\text { frequency }\end{array}$ & $\begin{array}{c}\text { Orthographic } \\
\text { congruency }\end{array}$ \\
\hline \multirow[t]{2}{*}[\mathrm{t}]{} & \multirow[t]{2}{*}{ 'metəl } & metal & 32.08 & 47.6 & \multirow{2}{*}{ N/A } \\
\hline & & mettle & 0.58 & 0.83 & \\
\hline \multirow[t]{2}{*}[\mathrm{t}]{} & \multirow[t]{2}{*}{ wDt } & what & 7264.17 & 1873.26 & \multirow{2}{*}{$\begin{array}{l}\text { Congruent } \\
\text { (watt) }\end{array}$} \\
\hline & & watt & 1.63 & 7.2 & \\
\hline \multirow[t]{2}{*}[\mathrm{t}]{} & \multirow[t]{2}{*}{ 'litərəl } & literal & 2.69 & 5.44 & \multirow{2}{*}{$\begin{array}{c}\text { Incongruent } \\
\text { (litorale) }\end{array}$} \\
\hline & & littoral & 0 & 0.46 & \\
\hline \multirow[t]{2}{*}{ [d] } & \multirow[t]{2}{*}{$æ d$} & $\mathrm{ad}$ & 12.1 & 29.37 & \multirow{2}{*}{$\begin{array}{l}\text { Congruent } \\
\text { (addizione) }\end{array}$} \\
\hline & & add & 106.82 & 80.1 & \\
\hline \multirow[t]{2}{*}{ [d] } & \multirow[t]{2}{*}{ 'medəl } & medal & 2.4 & 12.26 & \multirow{2}{*}{ N/A } \\
\hline & & meddle & 1.25 & 0.68 & \\
\hline \multirow[t]{2}{*}[\mathrm{n}]{} & \multirow[t]{2}{*}{ bænd } & band & 27.38 & 72.43 & \multirow{2}{*}{ N/A } \\
\hline & & banned & 6.34 & 20.25 & \\
\hline \multirow[t]{2}{*}[\mathrm{n}]{} & \multirow[t]{2}{*}{ 'finis } & finish & 89.24 & 39.21 & \multirow{2}{*}{$\begin{array}{l}\text { Congruent } \\
\text { (finnico) }\end{array}$} \\
\hline & & Finnish & 0.1 & 3.17 & \\
\hline \multirow[t]{2}{*}[\mathrm{n}]{} & \multirow[t]{2}{*}{ 'mænəz } & manors & 7.49 & 20.16 & \multirow{2}{*}{$\begin{array}{c}\text { Incongruent } \\
\text { (maniere) }\end{array}$} \\
\hline & & manners & 12.68 & 65.06 & \\
\hline \multirow[t]{2}{*}[\mathrm{n}]{} & 'tenə & tenor & 1.92 & 4.18 & $N / A$ \\
\hline & & tenner & 6.63 & 0.63 & $\mathrm{~N} / \mathrm{A}$ \\
\hline$[\mathrm{r}]$ & 'beri & bury & 6.53 & 9.16 & \\
\hline & & berry & 1.63 & 5.18 & N/A \\
\hline$[\mathrm{r}]$ & 'kærət & carat & 6.92 & 0.8 & Incongruent \\
\hline & & carrot & 7.59 & 3.39 & (carota) \\
\hline$[\mathrm{s}]$ & dı'sent & descent & 1.63 & 11.47 & Congruent \\
\hline & & dissent & 1.06 & 6.12 & (dissentire) \\
\hline$[\mathrm{s}]$ & mist & mist & 2.5 & 11.55 & $N / 4$ \\
\hline & & missed & 56.2 & 39.61 & N/A \\
\hline$[\mathrm{s}]$ & muis & moose & 1.15 & 0.97 & Congruent \\
\hline & & mousse & 2.4 & 2.21 & (mousse) \\
\hline$[\mathrm{z}]$ & $d_{I}^{\prime} z 3: t$ & desert & 7.4 & 22.77 & Congruent \\
\hline & & dessert & 0.77 & 3.32 & (dessert) \\
\hline$[1]$ & ə'laud & aloud & 1.54 & 10.43 & \\
\hline & & allowed & 104.32 & 128.19 & $\mathrm{~N} / \mathrm{A}$ \\
\hline$[1]$ & bild & build & 64.75 & 73.43 & N/A \\
\hline & & billed & 0.96 & 2.14 & $\mathrm{~N} / \mathrm{A}$ \\
\hline$[1]$ & paul & pole & 7.78 & 14.25 & $N / 4$ \\
\hline & & poll & 25.36 & 29.2 & N/A \\
\hline [1] & roul & role & 65.32 & 196.87 & Congruent \\
\hline & & roll & 39.96 & 31.39 & (rollare) \\
\hline
\end{tabular}




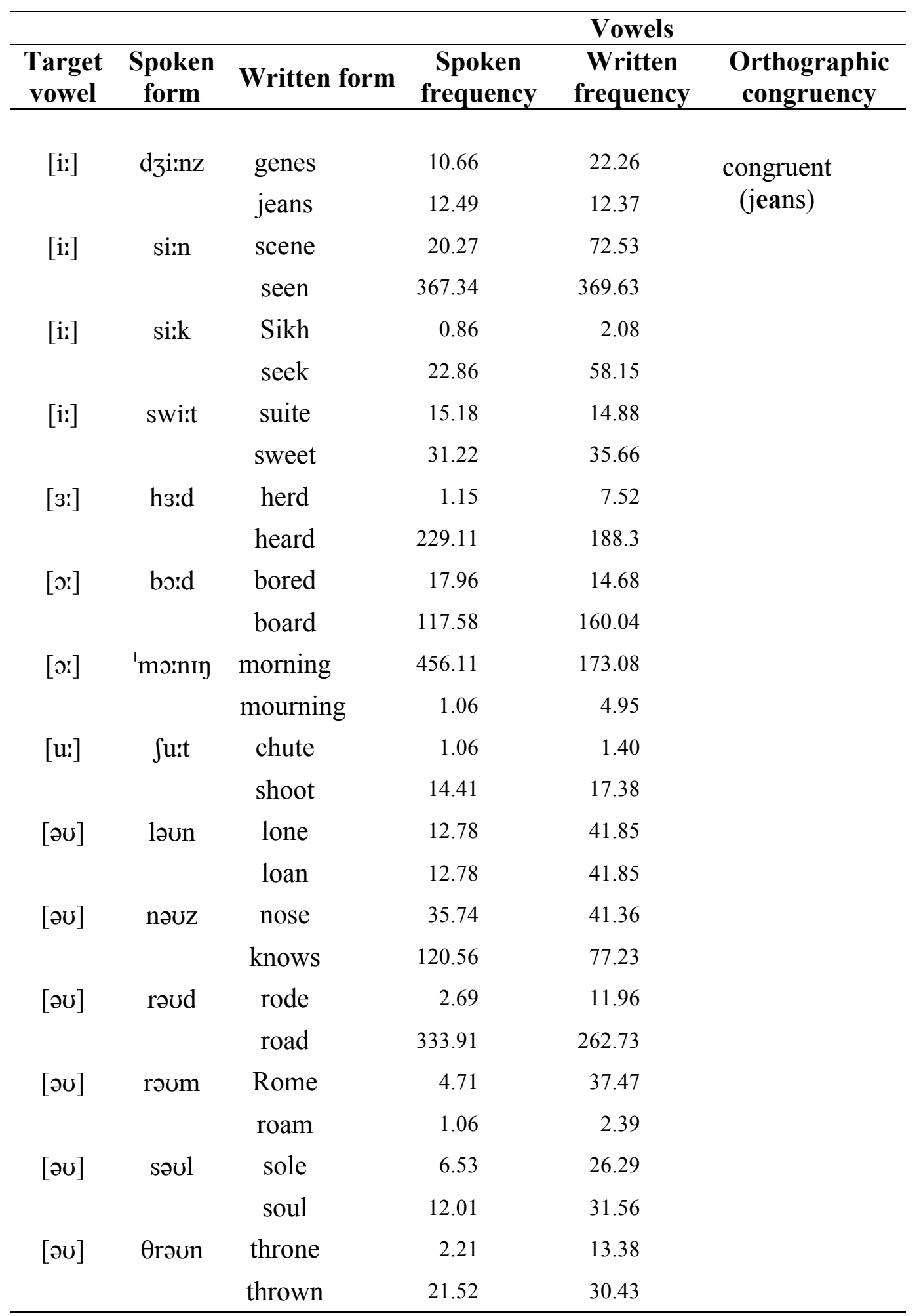


Bassetti, Sokolović-Perović, Mairano, \& Cerni (2018, online first) Orthography-induced length contrasts in the second language phonological systems of L2 speakers of English: Evidence from minimal pairs. Language and Speech.

DOI: $10.1177 / 002383091878014$

\section{Italian word reading aloud task materials}

Transcriptions from Canepari (2009), written frequencies from CoLFIS (Bertinetto et al., 2005), spoken frequencies from BADIP. Banca dati dell'Italiano parlato, Language server of Karl-Franzens-Universität Graz. Retrived from http://languageserver.uni-graz.at/badip (Banca Dati dell'Italiano Parlato)

\begin{tabular}{|c|c|c|c|c|}
\hline & & \multicolumn{3}{|c|}{ Consonants } \\
\hline $\begin{array}{l}\text { Target } \\
\text { sound }\end{array}$ & $\begin{array}{c}\text { Spoken } \\
\text { form }\end{array}$ & $\begin{array}{c}\text { Written } \\
\text { form }\end{array}$ & $\begin{array}{c}\text { Spoken } \\
\text { frequency }\end{array}$ & $\begin{array}{c}\text { Written } \\
\text { frequency }\end{array}$ \\
\hline$[\mathrm{p}]$ & kap & cap & 0 & 0.69 \\
\hline$[p(:)]$ & ap & app & 0 & 0 \\
\hline$[\mathrm{t}]$ & ka'zet:a & casetta & 0 & 0.57 \\
\hline$[\mathrm{t}:]$ & ka'sietta & cassetta & 47.02 & 7.98 \\
\hline$[\mathrm{t}]$ & 'greto & greto & 0 & 0.64 \\
\hline$\left[\mathrm{t}_{\mathrm{i}}\right]$ & 'gret:o & gretto & 0 & 0.57 \\
\hline$[\mathrm{t}]$ & 'rito & rito & 8.18 & 22.33 \\
\hline$\left[\mathrm{t}_{\mathrm{i}}\right]$ & 'rit:o & ritto & 0 & 0.26 \\
\hline$[\mathrm{t}]$ & ma'miut & mammut & 0 & 0.1 \\
\hline$[\mathrm{t}(\mathrm{:})]$ & ka'put & kaputt & 0 & 0 \\
\hline$[\mathrm{d}]$ & 'kade & cade & 24.53 & 19.22 \\
\hline$[\mathrm{d}:]$ & 'kad:e & cadde & 0 & 6.05 \\
\hline$[\mathrm{n}]$ & 'mini & $\operatorname{mini}$ & 4.09 & 5.37 \\
\hline$[\mathrm{n}:]$ & 'min:i & minnie & 2.04 & 0.56 \\
\hline [n] & 'vano & vano & 0 & 2.03 \\
\hline$[\mathrm{n}:]$ & 'van:o & vanno & 335.26 & 110.83 \\
\hline$[\mathrm{n}]$ & 'pakistan & pakistan & 2.04 & 1.07 \\
\hline$[\mathrm{n}(\mathrm{s})]$ & 'doberman & dobermann & 0 & 0.23 \\
\hline$[\mathrm{r}]$ & 'bara & bara & 4.09 & 4.72 \\
\hline$[\mathrm{r}:]$ & 'bar:a & barra & 22.49 & 0.8 \\
\hline$[\mathrm{r}]$ & 'scri & seri & 12.27 & 13.07 \\
\hline$[\mathrm{r}:]$ & 'scrii & serri & 0 & 0 \\
\hline$[\mathrm{z}]$ & po'zjamo & posiamo & 0 & 0.01 \\
\hline$[\mathrm{Si}]$ & po'sijamo & possiamo & 372.05 & 78.12 \\
\hline$[\mathrm{s}]$ & bis & bis & 2.04 & 6.44 \\
\hline$[\mathrm{s}(\mathrm{:})]$ & mis & miss & 4.09 & 8.06 \\
\hline$[1]$ & ko'lante & colante & 0 & 0 \\
\hline$[1:]$ & ko'liante & collante & 0 & 0.68 \\
\hline$[1]$ & $\mathrm{d}_{3} \varepsilon \mathrm{l}$ & gel & 2.04 & 1.17 \\
\hline$[1(:)]$ & $\mathrm{t} \int \varepsilon \mathrm{l}$ & cell & 0 & 0 \\
\hline
\end{tabular}


Bassetti, Sokolović-Perović, Mairano, \& Cerni (2018, online first) Orthography-induced length contrasts in the second language phonological systems of L2 speakers of English: Evidence from minimal pairs. Language and Speech.

\begin{tabular}{ccccc}
\hline $\begin{array}{c}\text { Target } \\
\text { sound } \\
{[\mathrm{i}]}\end{array}$ & $\begin{array}{c}\text { Spoken } \\
\text { form }\end{array}$ & $\begin{array}{c}\text { Written } \\
\text { form }\end{array}$ & $\begin{array}{c}\text { Spoken } \\
\text { frequency }\end{array}$ & $\begin{array}{c}\text { Written } \\
\text { frequency }\end{array}$ \\
{$[\mathrm{di}]$} & di & di & 24021.93 & 31198.41 \\
{$[\varepsilon]$} & dzii & zii & 2.04 & 2.51 \\
{$[\varepsilon \mathrm{e}]$} & 'd $\varepsilon \mathrm{e}$ & tè & 1760.10 & 15.25 \\
{$[\circ]$} & dee & 0 & 0.03 \\
{$[\circ \mathrm{o}]$} & 'dzoo & zoo & 6.13 & 5.84 \\
\hline
\end{tabular}

